\title{
Miniatividades sobre Conceitos Básicos de IHC: Dinamizando as Aulas Expositivas
}

\author{
Taciana Pontual Falcão \\ Departamento de Computação, Universidade Federal Rural de Pernambuco - UFRPE \\ Recife, Brasil \\ taciana.pontual@ufrpe.br
}

\begin{abstract}
RESUMO
Cada vez mais cobra-se inovação didática de professores, com o objetivo de adequar os métodos de ensino às novas gerações de estudantes. Entretanto, o compartilhamento de experiências e materiais didáticos para facilitar e acelerar esse processo ainda é pouco difundido entre professores. Alinhado à proposta do Workshop de Ensino de Interação Humano-Computador (WEIHC), esse artigo dá um passo nessa direção ao apresentar miniatividades que podem ser facilmente realizadas em aulas presenciais de uma disciplina básica de IHC, dinamizando as aulas expositivas e apoiando a construção de conhecimento por meio de uma participação ativa e lúdica dos estudantes.
\end{abstract}

\section{Palavras-chave}

Conceitos básicos de IHC; atividades práticas; aulas expositivas; participação ativa; ludicidade.

\section{ACM Classification Keywords}

H.5.2. Information interfaces and presentation (e.g., HCI): User Interfaces. K.3.2: Computers and Education: Computer science education.

\section{INTRODUÇÃO}

A inovação didática é uma constante busca na carreira docente, em qualquer nível de ensino. Faz parte desse processo incentivar a participação mais ativa dos estudantes, distanciando-se do modelo tradicional da transmissão de conhecimento que parte do professor, em que os estudantes têm como principal função ouvir e "apreender" [12]. De fato, com o baixo interesse dos estudantes percebido em aulas fortemente baseadas em exposição de conteúdos, professores vêm cada vez mais buscando alternativas [9].

Ainda é difícil, entretanto, substituir as aulas expositivas por um modelo plenamente construtivista. Uma das maiores

\footnotetext{
Permission to make digital or hard copies of all or part of this work for personal or classroom use is granted without fee provided that copies are not made or distributed for profit or commercial advantage and that copies bear this notice and the full citation on the first page. Copyrights for components of this work owned by others than the author(s) must be honored. Abstracting with credit is permitted. To copy otherwise, or republish, to post on servers or to redistribute to lists, requires prior specific permission and/or a fee. Copyright 2018 SBC
}

IHC 2018, Anais Estendidos do XVII Simpósio Brasileiro sobre Fatores Humanos em Sistemas Computacionais

Outubro 22-26, 2018, Belém, Brasil

Workshop sobre Educação em IHC (WEIHC) dificuldades que surgem é fazer os estudantes assumirem a responsabilidade pela sua própria aprendizagem, demonstrando suficientes iniciativa, engajamento e autonomia para que o professor possa se colocar como mediador em um processo produtivo de aprendizagem significativa centrada no estudante [8]. Ao longo de sua vida escolar, os estudantes ainda são acostumados a assumir uma postura predominantemente passiva, difícil de mudar quando eles chegam ao ensino superior.

Como uma solução meio-termo, temos experimentado em sala de aula mesclar miniatividades práticas com exposição de conteúdo, tornando as aulas mais dinâmicas e aproximando-se da aprendizagem ativa [9], fortalecendo a consolidação dos conceitos.

O objetivo desse artigo é compartilhar as miniatividades que vêm sendo realizadas e aprimoradas ao longo de nove edições de uma disciplina básica de IHC, entre 2013 e 2018, com turmas de 10 alunos em média, dos cursos de Licenciatura em Computação, Bacharelado em Ciência da Computação e Bacharelado em Sistemas de Informação, oferecida no turno da noite na Universidade Federal Rural de Pernambuco - UFRPE. As próximas seções apresentam as miniatividades e sua relação com conceitos de IHC.

\section{MINIATIVIDADES}

As miniatividades apresentadas a seguir são relacionadas a quatro conteúdos que podem ser abordados em disciplinas básicas de IHC [4,6]: modelos mentais; processos cognitivos; princípios e diretrizes de IHC; e acessibilidade. A escolha dos conteúdos não seguiu um critério particular apenas, para esses conteúdos do programa da disciplina, a professora e autora desse artigo conseguiu pensar em atividades práticas que deram bons resultados.

Cada miniatividade é contextualizada nessa seção da seguinte forma: objetivo da aula em que a miniatividade se insere; descrição de como a atividade é realizada; resultados comumente obtidos; e breve discussão pedagógica.

\section{Modelos Mentais}

Objetivo da aula

Fazer os alunos entenderem a interface de sistemas como a representação de um modelo conceitual, projetado a partir do modelo mental do designer, e que precisa ser compreendido por usuários com diferentes modelos mentais. 


\section{Miniatividade do borrão de tinta}

Inicia-se a primeira miniatividade com o slide mostrado na Figura 1, sem que tenha sido feita qualquer menção a modelos mentais. A figura é um dos "borrões" do teste de Hermann Rorschach (também conhecido como teste do borrão de tinta), uma técnica de avaliação psicológica pictórica desenvolvida no início do século XX. O objetivo da técnica é obter um quadro psicológico da pessoa a partir de suas interpretações de imagens com manchas de tinta simétricas ("pranchas") [3].

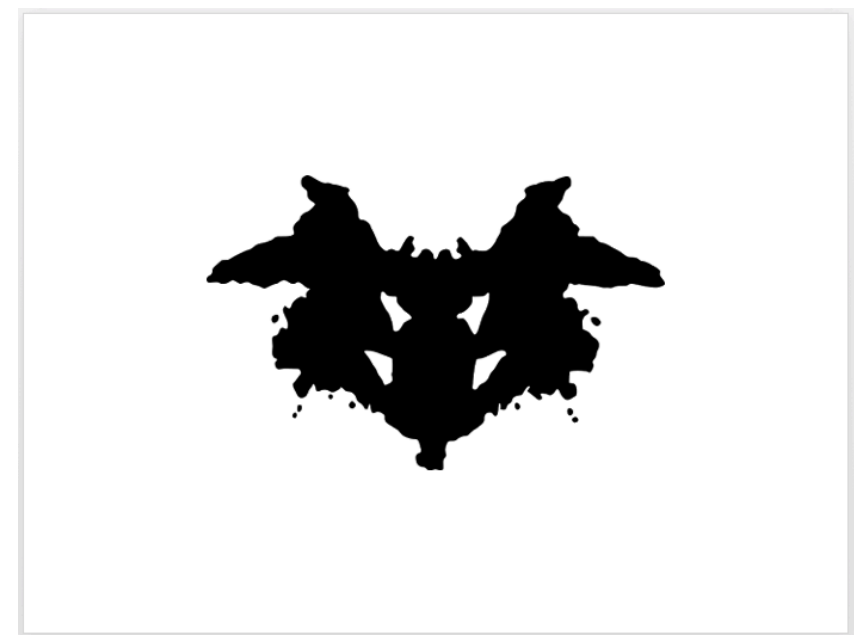

Figura 1. Slide inicial da aula sobre modelos mentais: prancha de Rorschach (domínio público).

Nessa miniatividade, pede-se aos estudantes apenas que eles observem a imagem e registrem a primeira coisa que lhes vêm em mente. Após alguns segundos, cada estudante deve verbalizar o que pensou. Nenhuma questão psicológica é abordada na aula: a imagem é usada simplesmente para introduzir o conceito de modelo mental e fazer uma rápida comparação entre as interpretações dos alunos.

As interpretações mais frequentes dos estudantes geralmente coincidem com as respostas registradas na literatura, associando a imagem a morcego ou borboleta (ou similares) [7]. Porém surgem também respostas como Pokemón e armaduras dos Cavaleiros do Zodíaco, claramente ligadas à idade média dos estudantes (em torno de 20 anos), e talvez também à predominância do sexo masculino. Se por um lado a coincidência com as respostas-padrão servem para evidenciar um modelo mental predominante mesmo considerando-se um público internacional e extremamente heterogêneo (o que suporta construção de interfaces direcionadas ao "usuário comum"), por outro lado as respostas que fogem do padrão permitem explorar a importância da cultura, contexto e perfil do público-alvo.

A aula prossegue com a apresentação da definição de modelo mental como uma representação produzida pela pessoa a partir de suas experiências com o mundo real, e outros exemplos lúdicos que ilustram diferenças de modelos mentais entre gerações, como: vídeos da série "Kids react to" [2], em particular "Kids react to old computers" (crianças reagem a antigos computadores); e charges como a da Figura 2. A Figura 2 permite fazer a ligação com as metáforas de interface, começando com ícones consolidados desde os anos 90, como o disquete para salvar e o envelope de papel para envio de correspondência eletrônica (email), que não fazem mais sentido para as novas gerações.

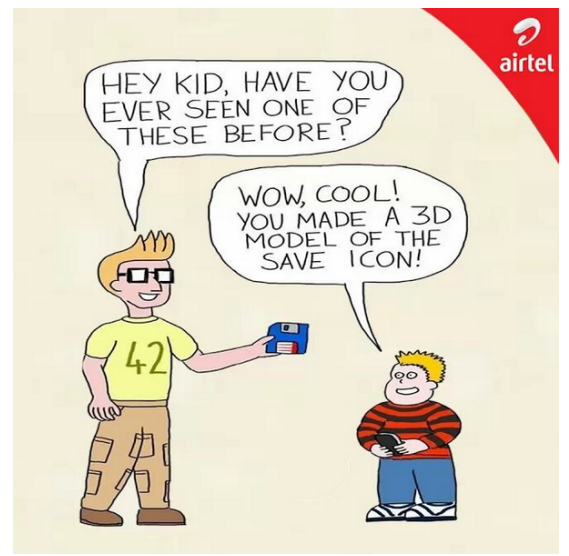

Figura 2. Exemplo lúdico de diferenças de modelos mentais entre gerações.

Miniatividade do envio de carta

Por fim, após a discussão sobre representações na interface e metáforas, aproveita-se a questão do ícone do envelope para fazer a segunda miniatividade, em que os estudantes devem individualmente descrever por escrito o processo para se enviar uma carta pelo serviço dos Correios. Após alguns minutos, voluntários compartilham suas produções, provendo novamente uma comparação de modelos mentais. É comum que muitos estudantes nunca tenham enviado cartas em papel e tenham apenas uma ideia geral do processo (não sabendo muito bem como funciona a lógica dos selos, por exemplo); enquanto outros, geralmente mais velhos, produzem descrições mais detalhadas. $\mathrm{O}$ objetivo pedagógico do exercício é mostrar com um exemplo concreto que os modelos mentais são visões da realidade individuais, dinâmicas, incompletas, e mais ou menos ricas em detalhes.

\section{Processos Cognitivos}

Objetivo da aula

Fazer os estudantes entenderem a importância dos processos cognitivos de percepção e memória na interação humanocomputador, e como essas questões impactam no projeto de interfaces.

\section{Miniatividade da Gestalt}

A miniatividade é apresentada aos estudantes como um exercício sobre a organização que o cérebro impõe ao mundo em termos de percepção, baseado nos princípios da Gestalt. São distribuídas fichas em papel aos estudantes com cinco imagens representando os princípios de: proximidade, similaridade, fechamento, continuidade e simetria (não revelados aos estudantes nesse momento) (Figura 3). 


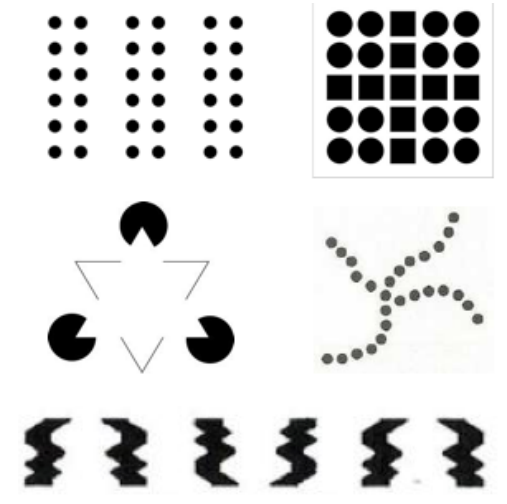

Figura 3. Ficha de exercício sobre princípios de Gestalt.

Os estudantes têm um tempo para marcar graficamente em cada imagem o que eles percebem, pensando na situação em que eles fossem descrever a imagem para alguém. Por exemplo, na imagem que ilustra proximidade, é esperado que os estudantes marquem os agrupamentos formados pelas duplas de colunas de círculos (conforme iniciado na Figura 4, à esquerda), o que corresponderia a uma descrição verbal como: "há três colunas duplas formadas por círculos alinhados" ou similar. Uma dificuldade dessa atividade é que os estudantes costumam ter muitas dúvidas com as instruções, e é comum que alguns não consigam entender o que é esperado deles até que se comece a compartilhar as percepções da turma. Porém, uma vez esclarecido o primeiro exemplo, a compreensão é imediata.

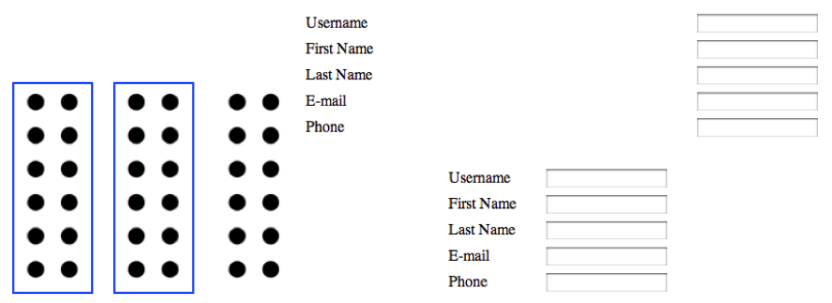

Figura 4. Exemplo de marcação esperada (esquerda) e exemplo de aplicação do princípio da proximidade em uma interface de software (direita).

Para o compartilhamento das respostas, o procedimento é o seguinte: cada imagem é projetada individualmente no quadro branco e um voluntário é chamado para fazer a marcação gráfica de sua percepção, usando o lápis para quadro branco por cima da imagem projetada. Em seguida, pergunta-se ao voluntário por que ele marcou a imagem daquela forma e se outros estudantes também o fizeram. $\mathrm{Na}$ maioria dos casos, a marcação corresponde à esperada, e assim, passando-se para o slide seguinte, projeta-se a marcação feita digitalmente (Figura 4, à esquerda), que coincide com a marcação a lápis feita pelo voluntário ${ }^{1}$. $\mathrm{Na}$ explicação do voluntário sobre os motivos que justificam a

\footnotetext{
${ }^{1}$ Caso o voluntário tenha marcado de forma diferente, as mesmas perguntas são feitas, mas em seguida é projetada e explicada a marcação esperada.
}

sua marcação, é comum que apareçam palavras relacionadas ao princípio em questão (por exemplo, no caso da proximidade, palavras como perto, junto, afastado, etc.). Daí faz-se a ligação para que os estudantes cheguem por eles mesmos à palavra exata que representa aquele princípio (nesse exemplo, "proximidade"). Conseguir que os estudantes enunciem o princípio tem sido muito mais eficaz pedagogicamente do que enunciar para eles. Por fim, são mostrados exemplos de interfaces que se utilizam do princípio em questão (Figura 4, à direita). O procedimento se repete para as cinco imagens, correspondentes aos cinco princípios abordados.

\section{Miniatividades de recordar e reconhecer}

As miniatividades sobre memória objetivam destacar três achados de pesquisa consolidados e muito relevantes para o projeto de interfaces: (i) a memória de curto prazo do ser humano tem uma capacidade limitada de 7 mais ou menos 2 elementos [10]; (ii) elementos conhecidos e significativos exigem menos tempo de processamento da memória de curto prazo; (iii) é mais fácil reconhecer do que relembrar.

Para tal, são realizados três experimentos em sala de aula com os estudantes. No primeiro experimento, projeta-se no quadro para os estudantes uma lista de 13 números, lidos pausadamente em voz alta, e em seguida ocultados. Os estudantes devem então anotar em um papel apenas os números que conseguem recordar. Quando todos terminam, a lista é novamente exibida e cada estudante verifica e informa quantos números acertou. É calculada a média de elementos que foram corretamente lembrados pela turma e o procedimento é repetido para uma lista de 13 palavras. Em seguida, os estudantes são informados sobre o experimento de George Miller sobre a capacidade de memória de curto prazo, e as duas médias obtidas são comparadas ao resultado padrão. Em nove edições da disciplina, todas as turmas obtiveram uma média de 7 mais ou menos 2 elementos recordados, como previsto pelo experimento original.

O segundo experimento segue o mesmo procedimento, porém a primeira lista apresentada é constituída de palavras compostas significativas (ex. chocolate quente, pop rock...), e a segunda lista é formada por duplas de palavras não significativas (ex. chocolate cracker, laser pop...). Os estudantes precisam lembrar as duplas de palavras (recordar uma palavra individualmente não contabiliza um acerto). Invariavelmente, os estudantes têm um desempenho melhor ao recordar elementos da primeira lista. Diante desse resultado, é apresentado aos estudantes o item (ii), sobre a dificuldade de se recordar elementos não significativos.

Por fim, para o terceiro experimento é mostrada uma lista que mistura palavras que fizeram parte dos experimentos anteriores com palavras que não apareceram. Os estudantes 
são convidados a responder sim ou não em voz alta, em conjunto, para cada palavra lida, caso ela tenha aparecido anteriormente ou não. Com raríssimas exceções, os estudantes costumam responder corretamente em um coro uníssono de "sim" e "não". Diante do sucesso no desempenho nessa tarefa, em particular comparado à dificuldade de recordar sentida nos experimentos anteriores, apresenta-se o item (iii), sobre a facilidade de reconhecer versus a dificuldade de relembrar.

A aula prossegue com exemplos de questões ligadas à memória em projetos de interface, tais como: funções de autopreenchimento; listas de favoritos; opções de gravar e recuperar senhas; características das perguntas de segurança; elementos de localização como trilhas de links; entre outros.

\section{Princípios e Diretrizes de IHC}

\section{Objetivo da aula}

Apresentar os principais princípios de IHC, incluindo as correlações entre princípios de diferentes autores de renome na área.

\section{Miniatividade de card sorting de princípios}

As heurísticas de Nielsen [11], as regras de ouro de Shneiderman [13] e os critérios ergonômicos de Bastien e Scapin [5] são rapidamente apresentados aos estudantes em um slide único. Em seguida, os princípios são distribuídos em três conjuntos de post-its, sendo uma cor para cada conjunto / autor (Figura 5). A ideia é realizar uma espécie de card sorting aberto, em que os estudantes, em grupo ${ }^{2}$, criam suas próprias categorias agrupando princípios que julgam relacionados. As categorias devem também ser nomeadas pelos estudantes. Os post-its são então colados no quadro ou na parede (agrupados nas categorias criadas), para usar como referência na continuação da aula.

Embora não existam respostas "certas", há agrupamentos esperados, como por exemplo, princípios relacionados a erros. Os agrupamentos feitos pelos estudantes têm variado consideravelmente entre turmas / grupos, percebendo-se alguns princípios menos compreendidos, em particular os critérios ergonômicos de Bastien e Scapin [5], por terem um foco maior em ergonomia e usarem uma linguagem menos familiar aos estudantes de Computação.

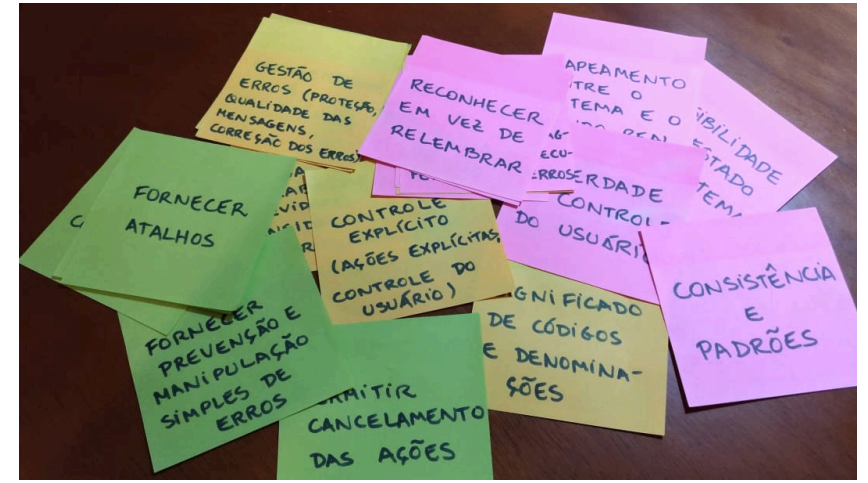

Figura 5. Três conjuntos de princípios de IHC separados por cores.

A aula prossegue com uma exposição de slides ilustrando as categorias (de mais alto nível do que os princípios) apresentadas por Barbosa e Silva [4] (capítulo 8 do livro didático adotado na disciplina), fazendo correlações com as categorias criadas pelos estudantes e refletindo sobre as diferenças - sem, porém, classificar em certo ou errado, pois o objetivo é familiarizar os estudantes com o conteúdo dos conjuntos de princípios, observar semelhanças, e refletir sobre os princípios de IHC.

\section{Miniatividade de bons e maus exemplos}

Ao final da aula, é feita uma segunda miniatividade, para consolidação dos princípios apresentados. São distribuídos aos estudantes, bons e maus exemplos de interfaces, impressos em papel. Os estudantes têm um tempo para refletir sobre o exemplo que receberam. Em seguida, cada exemplo é projetado no quadro, e o estudante que recebeu aquele exemplo deve ir até o quadro e explicar, com base nos princípios estudados, os motivos de ser um exemplo bom ou mau. Como a distribuição de exemplos é aleatória e a ordem dos slides também, ninguém sabe (nem o/a professor(a)) quem será o próximo a vir ao quadro - o que obriga os estudantes a ficarem atentos. $\mathrm{O}$ fato de criticar uma interface em frente à turma também faz com que os estudantes se esforcem para embasar bem a formulação de sua crítica (que pode ser positiva ou negativa).

\section{Acessibilidade}

Objetivo da aula

Apresentar conceitos básicos de acessibilidade digital e sensibilizar os estudantes para a importância de desenvolver sistemas acessíveis.

\section{Miniatividade da Bengala Legal}

A miniatividade é realizada após apresentar os principais conceitos relacionados a acessibilidade digital, e algumas técnicas simples para construir sites acessíveis, dentre elas o uso da descrição de imagens.

Para promover a empatia dos estudantes com usuários cegos, um texto descritivo de uma imagem é lido em voz alta, para

\footnotetext{
${ }^{2}$ Em turmas pequenas, é possível fazer um grupo único.
} 
que eles desenhem a imagem da forma como conseguem imaginá-la. Não por acaso, a imagem usada foi escolhida de um site sobre acessibilidade, o Bengala Legal [1] criado por Marco Antonio Queiroz (o MAQ), especialista consultor em acessibilidade na web, cego. Por esse motivo, o texto descritivo da imagem é extremamente detalhado, conforme transcrito a seguir:

Toda a logomarca está contida em uma imagem de uma folha de papel branco, pendurada por dois barbantes, que passam por dois furos nas extremidades. Nessa folha está desenhado o título "Bengala Legal" em uma única linha, e um boneco de rosto e óculos redondos (smiley). $O$ primeiro $L$ de legal coincide com o corpo do boneco e dele saem os dois braços: um deles faz o $V$ de vitória e o outro segura o $L$ de Bengala (como se fosse uma bengala). Abaixo tem o endereço do site www.bengalalegal.com entre duas tarjas. A ideia geral que a logomarca passa para quem vê é a de um desenho alegre e atual.

O texto é lido pausadamente aos estudantes quantas vezes forem necessárias para que capturem informações suficientes (geralmente duas ou três). Após a leitura e a conclusão dos desenhos, a imagem é revelada aos estudantes e os desenhos são passados de mão em mão para que todos conheçam os resultados. A atividade costuma divertir bastante os estudantes. Alguns exemplos de desenhos são mostrados na Figura 6.

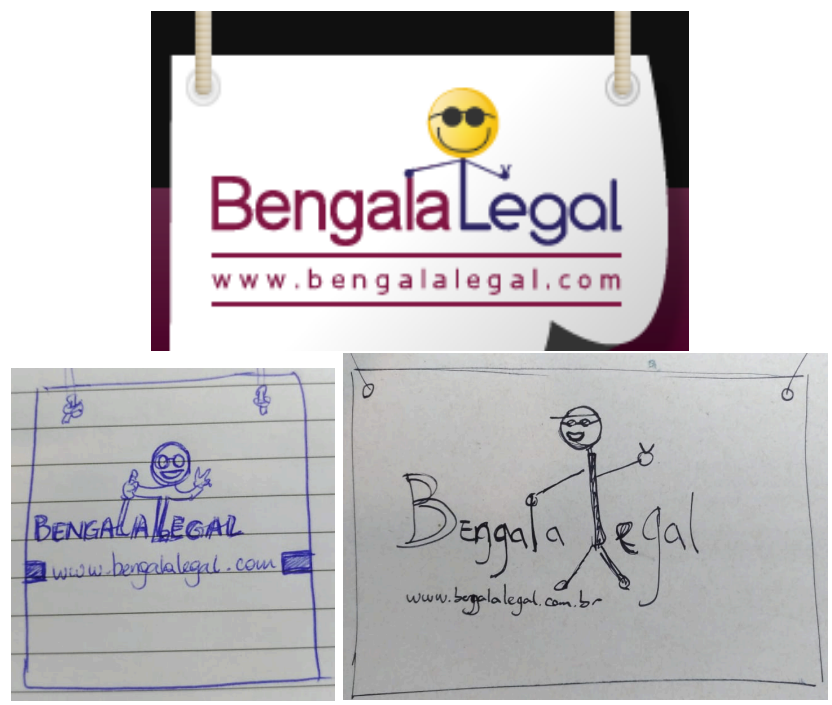

Figura 6. Logo do site Bengala Legal (cima) e desenhos dos estudantes a partir do texto descritivo da imagem (baixo).

\section{DISCUSSÃO}

Todas as miniatividades apresentadas possuem uma forte correlação com o conteúdo da aula, são de rápida e simples execução, e demandam pouco tempo de preparação e pouco material adicional além do quadro branco, computador com projetor, papel e lápis (como indicado na Tabela 1).

\begin{tabular}{c|cc} 
Miniatividade & $\begin{array}{c}\text { Conteúdo } \\
\text { relacionado }\end{array}$ & $\begin{array}{c}\text { Material } \\
\text { especial }\end{array}$ \\
\hline Borrão de tinta & Modelo mental & $\begin{array}{c}\text { Prancha de } \\
\text { Rorschach ou } \\
\text { similar }\end{array}$ \\
\hline Envio de carta & Modelo mental & - \\
\hline Gestalt & Percepção & $\begin{array}{c}\text { Fichas de } \\
\text { exercício }\end{array}$ \\
\hline $\begin{array}{c}\text { Recordar e } \\
\text { reconhecer }\end{array}$ & Memória & Calculadora \\
\hline $\begin{array}{c}\text { Card sorting } \\
\text { de princípios }\end{array}$ & $\begin{array}{c}\text { Princípios de } \\
\text { IHC }\end{array}$ & $\begin{array}{c}\text { Post-its em 3 } \\
\text { cores }\end{array}$ \\
\hline $\begin{array}{c}\text { Bons e maus } \\
\text { exemplos }\end{array}$ & $\begin{array}{c}\text { Princípios de } \\
\text { IHC }\end{array}$ & $\begin{array}{c}\text { Exemplos de } \\
\text { interface } \\
\text { impressos }\end{array}$ \\
\hline Bengala legal & Acessibilidade & -
\end{tabular}

Bengala legal Acessibilidade

Tabela 1. Visão geral das miniatividades.

Embora o compartilhamento das produções / opiniões dos estudantes nas atividades gere, de certa forma, comparação, as atividades não estimulam a competição, mas uma análise de resultados coletivos que se justifica pedagogicamente, e que é realizada em um clima amigável. Não houve, em nenhuma das nove edições da disciplina, reclamações de constrangimento individual. Outras atividades mais competitivas, em formato de minijogos, foram também experimentadas, porém a competição acirrada entre os estudantes, embora tenha levado a um alto engajamento, desviou excessivamente o foco do conteúdo. Por esse motivo, têm sido priorizadas atividades menos competitivas.

As miniatividades ajudam a aumentar a participação ativa dos estudantes na aula, quebrando a monotonia que pode decorrer da aula expositiva. Elas têm uma boa dose de ludicidade que costuma entreter os estudantes e prender sua atenção. $\mathrm{O}$ envolvimento deles claramente aumenta a cada transição da exposição de conteúdo para uma atividade prática, durante as aulas, da mesma forma que se nota uma nova dispersão ao retomar os slides conteudistas, dos quais ainda necessitamos. Por outro lado, percebe-se também certa insegurança dos estudantes em atividades em que possuem muita "liberdade", e em que a professora não impõe a dicotomia do certo / errado, mas promove a construção coletiva do conhecimento (por exemplo na atividade de card sorting com princípios e diretrizes).

Embora essas sejam impressões decorrentes apenas da prática docente da autora desse artigo, sem que tenha sido estruturada uma pesquisa científica para investigar a efetividade das atividades, percebe-se uma consonância com a literatura sobre aprendizagem ativa [9].

\section{CONCLUSÃO}

Nesse artigo, descrevemos sete miniatividades que podem ser realizadas ao longo de uma disciplina básica de IHC no 
ensino superior, em aulas presenciais. Acreditamos que todos podemos nos beneficiar do compartilhamento de experiências e materiais didáticos, que ainda precisa ser mais estimulado entre os docentes da comunidade de IHC, sendo o WEIHC um excelente fórum para tal. Com esse artigo esperamos dar mais um passo nessa direção.

Além do compartilhamento de experiências didáticas, os resultados desse artigo também apontam nichos de pesquisaação, em que os docentes de IHC analisem sua prática de forma sistemática, e possam embasar suas decisões pedagógicas em resultados científicos, assim contribuindo para o avanço e melhoria da educação em Computação.

\section{AGRADECIMENTOS}

A todos os estudantes que cursaram a disciplina de Interfaces Homem-Máquina na Universidade Federal Rural de Pernambuco, entre 2013 e 2018.

\section{REFERÊNCIAS}

1. Bengala Legal, 2013. Acesso em 4 de Julho de 2018, http://www.bengalalegal.com.

2. FBE, 2014. Kids react to old computers. Acesso em 4 de Julho de 2018, https://www.youtube.com/watch?v=PF7EpEnglgk.

3. The Original Rorschach Website, 2014. Acesso em 4 de Julho de 2018, http://www.rorschach.org/.

4. Simone D. J. Barbosa e Bruno S. da Silva. 2010. Interação Humano-Computador (1a ed.), Elsevier, Rio de Janeiro.

5. Christian Bastien e Dominique Scapin. 1993. Ergonomic Criteria for the Evaluation of HumanComputer interfaces, Institut National de recherche en informatique et en automatique, France.

6. Clodis Boscarioli, Milene S. Silveira, Raquel O. Prates, Sílvia Amélia Bim, e Simone D. J. Barbosa. 2014. Currículos de IHC no Brasil: Panorama Atual e Perspectivas. Em Anais do XXII Workshop sobre Educação em Computação, 1294-1303.

7. Alvin G. Burstein and Sandra Loucks. 1989. Rorschach's test: scoring and interpretation. Hemisphere Pub. Corp., New York, p. 72.

8. Jennifer Fredricks, Phyllis Blumenfeld, and Alison Paris. 2004. School engagement: Potential of the concept, state of the evidence. In: Review of educational research, Sage Publications, 74, 59-109.

9. Joel Michael. 2006. Where's the evidence that active learning works? Advances in Physiology Education, 30, 159-167.

10. George A. Miller. 1956. The magical number seven, plus or minus two: Some limits on our capacity for processing information. Psychological Review, 63, 8197.

11. Jakob Nielsen and Rolf Mohlic. 1990. Heuristic evaluation of user interfaces, In Proceedings of the
SIGCHI Conference on Human Factors in Computing Systems (CHI'90).

12. Dermeval Saviani. 2003. Pedagogia histórico-crítica: primeiras aproximações, $8^{\mathrm{a}}$ edição, Campinas, Autores Associados.

13. Ben Schneiderman. 1998. Designing the user interface ( $3^{\text {rd }}$ ed.), Addison Wesley, Reading, MA. 